\title{
Proposed Scales for Measuring Suicidal Ideation in Adult Cancer Patients
}

\author{
Diego Armando Leal-Hernández, Lucía Sandoval, \\ Ximena Palacios-Espinosa*, José Rafael Tovar Cuevas \\ Universidad del Rosario, Bogotá, Colombia \\ Email: dinewbie@gmail.com, lusandov@gmail.com, ximena.palacios@gmail.com, jose.tovarc@urosario.edu.co
}

Received September 27, 2013; revised October 27, 2013; accepted November 5, 2013

Copyright (C) 2014 Diego Armando Leal-Hernández et al. This is an open access article distributed under the Creative Commons Attribution License, which permits unrestricted use, distribution, and reproduction in any medium, provided the original work is properly cited. In accordance of the Creative Commons Attribution License all Copyrights (C) 2014 are reserved for SCIRP and the owner of the intellectual property Diego Armando Leal-Hernández et al. All Copyright @ 2014 are guarded by law and by SCIRP as a guardian.

\section{ABSTRACT}

Suicidal ideation, which can occur in oncology patients, is associated with suffering and a reduced quality of life. Empirical studies indicate that the incidence of suicide in people with cancer is approximately twice that of the general population. Objective: This cross-sectional descriptive study was designed to establish the prevalence of suicidal ideation in adult oncology patients based on a combination of scales to measure this variable. Method: A battery of three instruments (Scale for Suicidal Ideation. Item 9 of Beck's Depression Inventory, and a semistructured interview) was used to make estimates that are not based on just one test and can thus make a comprehensive evaluation of suicidal ideation in the study sample. Four approximations, based on different items from suicidal ideation assessment scales, were developed to determine the most sensitive combination for identifying the presence of suicidal ideation in adult cancer patients. Results: The highest prevalence of suicidal ideation found with the proposed scales was $24.5 \%(C I=16 \%-33 \%)$ with Scale $1 ; 23.6 \%(C I=15.2 \%-32 \%)$ with Scale 2; and $19.1 \%(C I=11.3 \%-26.9 \%)$ with Scale 4. The lowest prevalence of suicidal ideation was $17.3 \%$ (CI $=9.8 \%-24.8 \%$ ) with Scale 3. Conclusions: Suicidal behavior in the oncology patient should be assessed; however, there is a need to select sensitive instruments that can be applied easily and are suitable for the target group, which faces difficulties in participating in extensive evaluations.

\section{KEYWORDS}

Cancer; Suicidal Ideation; Assessment Scales

\section{Introduction}

Studies about suicidal behavior in people with cancer are few. However, the study by Robson et al. showed that the mortality rate from completed suicides in this population ranges from 1 - 11 [1]. These authors also found that while suicidal ideation in the general population had a prevalence ranging from $1.1 \%-19.8 \%$, it ranged from $0.8 \%-71.4 \%$ in the oncology population.

A study in which the Scale for Suicidal Ideation (SSI) was applied to patients with cancer who were receiving chemotherapy treatment in Mexico showed that 20\% of them had suicidal ideation [2]. Studies concur that the

\footnotetext{
"Corresponding author.
}

incidence of suicide in people with cancer is approximately double that of the general population [3-4]. With respect to gender, the same studies suggest that the risk of suicide is greater in men with cancer and increases with age, the same as in the general population; thus male patients over 65 have higher rates of suicide, reaching the highest levels after the age of 80 .

On the whole it is quite complex to obtain reliable estimates of suicidal ideation and suicide attempts in the oncology population due to the fact that most data come from retrospective reports [5]. Moreover, the information can also be affected by suicide-related taboos and stigmas which can cause people to hide information or not mention how death occurred [1-6]. 
In Colombia there are few studies about suicidal behavior in patients with cancer. In 1994, Barrera and Sarmiento conducted a descriptive study of 10 children with cancer, ranging in age from 8 - 10, who were hospitallized in the Oncology Units of two hospitals in Bogotá [7]. The objective was to identify suicidal ideation through the cognitive-affective schema of depression and hopelessness. Although 8 of the children were found to be suffering from these negative emotions, only one was found to have suicidal ideation.

It is now recognized that the presence of depression can lead to suicidal ideation in patients with cancer; even the support materials on this population indicate the importance of checking for its presence [8]. Furthermore, even when the emotional suffering (e.g. coping with multiple losses, recurrent fears, distress, uncertainty, frequent exposure to failure, demoralization, depression, anxiety) of oncology patients is well known, in many cases they do not receive assessment or treatment [6]; and it is unlikely that the psychosocial assessments and interventions will emphasize suicidal behavior. In fact, suicide is not usually assessed or discussed in the medical or psychiatric contexts, not even in those patients who do commit suicide or attempt to do so a short time after being treated medically [9].

The foregoing places in evidence a problem of interest in the area of oncology, specifically that of psycho-oncology: the patient with cancer does contemplate suicide and can carry it out. Therefore, it is necessary to assess this aspect as a part of the intervention and treat it in the event of detecting any type of risk.

The objective of this study was to establish the prevalence of suicidal ideation in adult oncology patients based on several proposed scales to measure this variable. Within the framework of this study, suicidal ideation is defined as the cognitive representation of the suicidal act [10], which occurs when the patient thinks about, plans or wishes persistently to commit suicide.

\section{Method}

\subsection{Research Type and Design}

This is a descriptive cross-sectional study designed to establish the prevalence of suicidal ideation through a set of indexes constructed using the information obtained from the application of a battery of instruments validated for assessing suicidal ideation, depression and despair. The methodological proposal focused on conducting a statistical analysis aimed at identifying scale items suitable for the sensitive measurement of suicidal ideation in the target population.

\subsection{Population and Sample}

The reference population consisted of adult oncology patients (Table 1). The sample consisted of one hundred ten (110) patients of both sexes, all adults over 18, diagnosed with cancer, who receive oncological treatment at a private center in the city of Bogotá (Colombia).

\subsection{Instruments}

With full cognizance of the diagnostic limitations of a psychometric test and in accordance with Article 47 (regarding the use of psychotechnical material) of the Deontological and Bioethical Code for exercising the profession of Psychology in Colombia, the central referent was that a diagnosis requires an in-depth and comprehensive analytical process. Although the purpose of this study was not to conduct a clinical diagnostic assessment, the precaution was taken to use a battery of three instruments, which made it possible to make estimates that were not based on just one test and can thus provide a comprehensive assessment of suicidal ideation in the study sample.

The instruments of this battery, which are described below, were applied, requesting the patients to respond based on their personal experience with cancer and all are in Spanish language.

The Scale for Suicidal Ideation (SSI), developed by Beck, Kovacs and Weissman, quantifies and assesses both the suicidal intents and their degree and intensity in the present and in the past [11]. Although it has not been validated in Colombia, there are versions available in Spanish. What is interesting about this scale is that it is based on a semi-structured interview and provides information about several dimensions: 1) attitude towards life and death, 2) suicidal thoughts or wishes, 3) a project contemplating suicide, and 4) carrying out a contemplated suicide attempt. The scoring for each item is from $0-2$, and the total score range is from 0 - 38; the higher the score, the greater the risk of suicide. At the end of the SSI, there are two items that assess the suicidal history; and although they are not included in the total scoring, they do have a descriptive value. We apply the scale in the form of interview looking the patient feel comfortable, quiet and increase their availability to communicate sensitive aspects of his life such as the wish to die, suicidal ideation and generally talk about suicide. Always asking questions in relation to the time they were diagnosed ("since you knew that you have cancer...").

Only item 9 of Beck's Depression Inventory (BDI), amended version (BDI-1A), assesses the risk of suicide and has been used in other studies for this purpose [12, 13].

The Semi-structured Interview (Intv.), which assesses suicidal symptoms in patients with cancer, was developed by the research team [14], with the objective of identifying suicidal ideation and suicide-related risk fac- 
Table 1. Characterization of the sample.

\begin{tabular}{|c|c|c|c|}
\hline & Variable & Frequency & $\%$ \\
\hline \multirow{4}{*}{$\begin{array}{l}\text { Place of } \\
\text { evaluation }\end{array}$} & Chemotherapy room & 31 & 28.2 \\
\hline & $\begin{array}{l}\text { Room where patient } \\
\text { was hospitalized }\end{array}$ & 61 & 55.5 \\
\hline & Office for outpatients & 18 & 16.4 \\
\hline & Total & 110 & 100 \\
\hline \multirow{4}{*}{$\begin{array}{l}\text { Age range } \\
\text { (years) }\end{array}$} & 18 to 40 & 39 & 35.5 \\
\hline & 41 to 60 & 55 & 50 \\
\hline & $\geq 61$ & 16 & 14.5 \\
\hline & Total & 110 & 100 \\
\hline \multirow{3}{*}{ Sex } & Feminine & 58 & 52.7 \\
\hline & Masculine & 52 & 47.3 \\
\hline & Total & 110 & 100 \\
\hline \multirow{6}{*}{ Civil status } & Single & 34 & 30.9 \\
\hline & Married & 47 & 42.7 \\
\hline & Free union & 14 & 12.7 \\
\hline & Widow(er) & 4 & 3.6 \\
\hline & Separated/divorced & 11 & 10 \\
\hline & Total & 110 & 100 \\
\hline \multirow{5}{*}{ Religion } & Catholic Christian & 86 & 78.2 \\
\hline & Non-Catholic Christian & 16 & 14.6 \\
\hline & Other & 3 & 2.7 \\
\hline & None & 5 & 4.5 \\
\hline & Total & 110 & 100 \\
\hline \multirow{6}{*}{$\begin{array}{l}\text { Location of } \\
\text { cancer }\end{array}$} & Soft tissues & 42 & 38.2 \\
\hline & Gastrointestinal tract & 36 & 32.7 \\
\hline & Breast & 12 & 10.9 \\
\hline & Reproductive system & 14 & 12.7 \\
\hline & Other & 6 & 5.5 \\
\hline & Total & 110 & 100 \\
\hline \multirow{6}{*}{ Stage } & I & 3 & 2.7 \\
\hline & II & 8 & 7.3 \\
\hline & III & 27 & 24.5 \\
\hline & IV & 22 & 20 \\
\hline & Not reported & 50 & 45.5 \\
\hline & Total & 110 & 100 \\
\hline
\end{tabular}

tors. In addition to the 27 items, there is a section of general information based on which the patient's sociode- mographic data, among others, are obtained. Eight of these items (1, 1.1, 3, 5, 7-10) are adapted for our study of Roth \& Holland research ${ }^{1}$ [15].

These instruments were selected because they have been used in clinical practice of some authors with cancer patients who share the characteristics of patients who participated in this study.

\subsection{Procedure}

Initially, control tests were applied to verify the consistency in the answers the patients gave on the instruments.

Subsequently, four approaches were developed from different scales to determine which of those combinations was the most sensitive for identifying the presence of suicidal ideation in adult cancer patients. Table 2 presents the scales with the items selected from each of the instruments, the maximum points for each scale, and the value of each item.

Although the range of total scores for each scale varies for the different proposed scales (Table 2), it was considered that a score greater than one (1) indicates that there is some grade of suicidal ideation and risk of suicide; thus, the higher the score, the greater the risk of suicide.

The items that were selected to form the approximations of the scales were those taken from the original tests that were oriented toward identifying the presence of suicidal ideation, more than assessing their structuring and intensity. Similarly, the selected items made it possible to assess the death wish, which according some authors should be included in assessing the risk of suicide [16]. Questions about the history of suicidal attempts were not included because it was considered that although it is a risk factor for suicide, it does not measure the current ideation.

Based on the patient's answers to the questions that made up the proposed scales, a concordance analysis including confidence intervals for the percentage of concordant cases in the quadrants for classifying the scales was done. Based on the information obtained from each scale, the prevalence of suicidal ideation and the $95 \%$ confidence interval were estimated.

\section{Ethical Aspects}

The research, within which this study was designed, evaluated and approved by the Ethics Committee of the Clinic where the oncology patients were assessed. The research was considered to have minimal risk according to Resolution 008430 of 1993 [17]. Throughout the

\footnotetext{
${ }^{1}$ Roth AJ, Holland JC: Psychiatric complications in cancer patients. In: Brain MC, Carbone PP, eds.: Current Therapy in Hematology-Oncology. 5th ed. St. Louis, Mo: Mosby-Year Book, Inc., 1995, pp. 609-618. Available in Table 7 "Suggested Questions for the Assessment of Suicidal Symptoms in People with Cancer”:

http://www.cancer.gov/cancertopics/pdq/supportivecare/depression/He althProfessional/page5.
} 
Table 2. Scales, maximum score and value for each item.

\begin{tabular}{|c|c|c|c|c|}
\hline & \multicolumn{3}{|c|}{ Original instrument } & \\
\hline & SSI & Intv. & BDI-1A & \\
\hline Score for each item & 0 to 2 & 0 to 1 & 0 to 3 & \\
\hline Items selected & $\begin{array}{l}\text { 2. Wish to die } \\
\text { moderate to strong (2); weak (1); none (0) } \\
\text { 3. Reasons for living/dying? } \\
\text { for living outweigh for dying (0) } \\
\text { about equal (1) } \\
\text { for dying outweigh for living (2) } \\
\text { 4. Desire to make active suicide attempt } \\
\text { moderate to strong (2); weak (1); none (0) }\end{array}$ & $\begin{array}{l}\text { 1. The majority of people } \\
\text { with cancer have passing } \\
\text { suicidal thoughts such as: "I } \\
\text { might do something if things } \\
\text { get too difficult... I'd rather } \\
\text { be dead, die or kill myself."* } \\
\text { 1.1. Have you had thoughts } \\
\text { of that type? I mean thoughts } \\
\text { of not wanting to live or } \\
\text { wishes that the illness would } \\
\text { hasten your death?" } \\
\text { Yes__ No _ } \\
\text { 2. Since you learned that } \\
\text { you have cancer. Have } \\
\text { you wanted to die? } \\
\text { Yes _ No _ } \\
\text { 3. Have you thought about } \\
\text { the way you would do it?* } \\
\text { Yes _ No _ }\end{array}$ & $\begin{array}{l}\text { 9. (0) I don't have any } \\
\text { thoughts of killing myself. } \\
\text { (1) In have thoughts of } \\
\text { killing myself, but I would } \\
\text { not carry them out. (2) I } \\
\text { would like to kill myself. } \\
\text { (3) I would kill myself if I } \\
\text { had the chance. }\end{array}$ & \\
\hline New scales & \multicolumn{3}{|c|}{ Items included in scale } & $\begin{array}{c}\text { Maximum } \\
\text { score }\end{array}$ \\
\hline Scale 1 & $\mathrm{X}$ & $\mathrm{X}$ & $\mathrm{X}$ & 12 \\
\hline Scale 2 & $\mathrm{X}$ & $\mathrm{X}$ & & 9 \\
\hline Scale 3 & & $\mathrm{X}$ & $\mathrm{X}$ & 6 \\
\hline Scale 4 & $X$ & & $X$ & 9 \\
\hline
\end{tabular}

*Adapted of Roth A.J., Holland J.C. "Psychiatric complications in cancer patients”. In: M.C. Brain, P.P. Carbone. eds.: “Current Therapy in Hematology-Oncology”. 5th ed. St. Louis, Mo: Mosby-Year Book, Inc., 1995, pp. 609-18. Available in Table 7 "Suggested Questions for the Assessment of Suicidal Symptoms in People with Cancer”: http://www.cancer.gov/cancertopics/pdq/supportivecare/depression/HealthProfessional/page5.

assessment process, informed consent was always obtained, and stress was placed on voluntary participation and confidentiality of the information.

\section{Results}

The prevalence of suicidal ideation was obtained in two ways: based on (1) the original scales and (2) the proposed scales. It was found that the highest prevalence of suicidal ideation with the original scales was $17.3(\mathrm{CI}=$ $9.8 \%-24.8 \%$ ) based on the SSI; while the lowest prevalence was $4.5 \%$ (CI $=1.5 \%-10.3 \%$ ) with Item 9 of the BDI-1A (Figure 1).

The highest prevalence of suicidal ideation found with the proposed scales was $24.5 \%(\mathrm{CI}=16 \%$ - 33\%) with Scale $1 ; 23.6 \%(\mathrm{CI}=15.2 \%$ - 32\%) with Scale 2; $19.1 \%$ $(\mathrm{CI}=11.3 \%$ - 26.9\%) with Scale 4 . The lowest prevalence found with the proposed scales was $17.3 \%$ (CI = 9.8\% - 24.8\%) with Scale 3 (Figure 1).

With respect to concordance analysis, it was found that the highest concordances were found between the pro- posed scales 1 and 2, with 99.1\% and a CI of 95\% 99.9\%; and between Scale 3 and the Intv. with exactly the same data (Table 3).

The lowest concordances were found between Scale 1 and Item 9 of the BDI-1A with a value of $80 \%$ and a CI of $72.1 \%-87.9 \%$, and between Scale 2 and Item 9 of the BDI-1A with a concordance of $79.1 \%$ and a CI of $71 \%$ $87.1 \%$.

These data were statistically significant with a ( $\mathrm{p}=$ 0.001 ) for the concordance between Scale 1 and Item 9 of the BDI-1A and a ( $\mathrm{p}=0.011$ ) for the concordance between Scale 2 and Item 9 of the BDI-1A (Table 3).

Table 4 shows the characterization of the patients with suicidal ideation according to the four proposed scales.

With Scale 1 (which brings together all the selected items that were used in the other proposed scales), almost half the patients who had suicidal ideation (48.1\%) were from 41 - 60 years of age; the majority were women (59.3\%); 37\% were single and the same percent were married. A diagnosis of soft-tissue cancer was the com- 


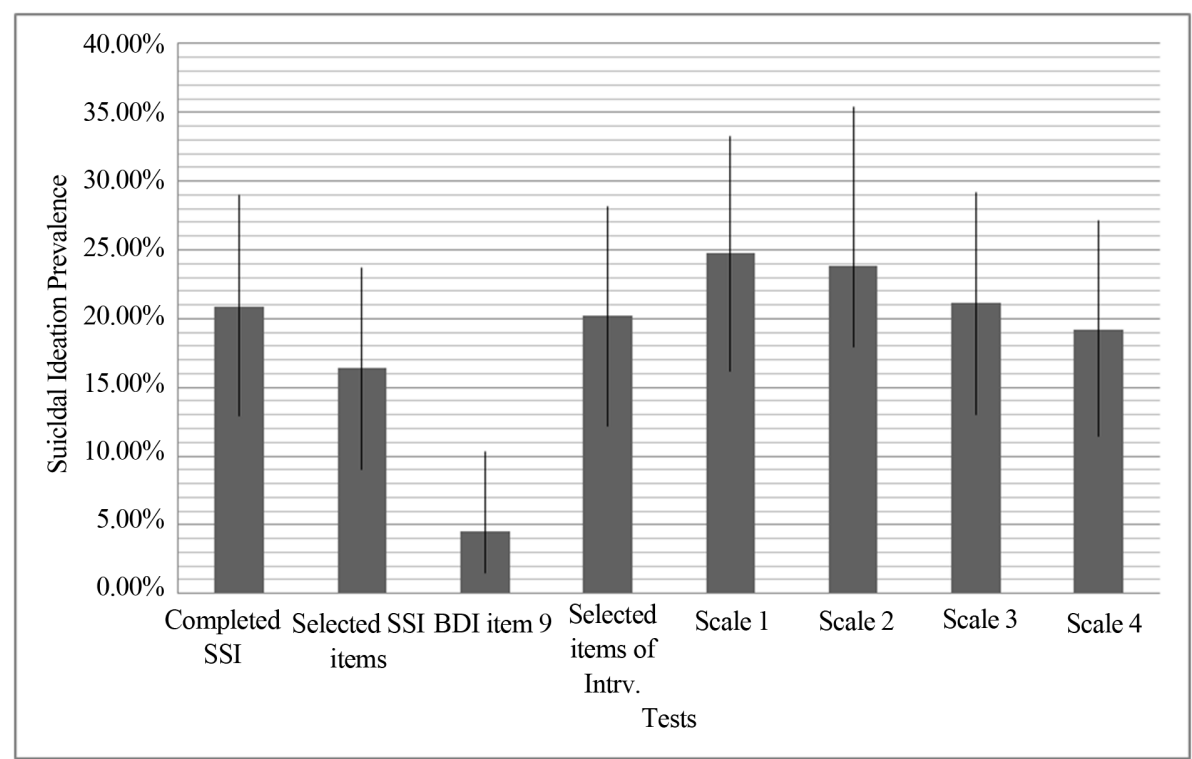

Figure 1. Prevalence of suicidal ideation according to the original instruments (tests) and the proposed scales.

Table 3. Contingencies, convergence and confidence intervals between the original instruments-scales and scalesscales.

\begin{tabular}{ccc}
\hline Contingencies & Concordance & Confidence intervals \\
\hline Scale 1-Beck & $80 \%$ & $72.1 \%-87.9 \%$ \\
Scale 1-SSI & $91.80 \%$ & $86.2 \%-97.4 \%$ \\
Scale 1-Intv. & $91.80 \%$ & $86.2 \%-97.4 \%$ \\
Scale 2-Beck & $79.10 \%$ & $71 \%-87.1 \%$ \\
Scale 2-SSI & $92.70 \%$ & $87.4 \%-98 \%$ \\
Scale 2-Intv. & $92.70 \%$ & $87.4 \%-98 \%$ \\
Scale 3-Beck & $87.30 \%$ & $80.6 \%-93.9 \%$ \\
Scale 3-SSI & $84.50 \%$ & $77.3 \%-91.8 \%$ \\
Scale 3-Intv. & $99.10 \%$ & $95 \%-99.9 \%$ \\
Scale 4-Beck & $85.50 \%$ & $78.4 \%-92.5 \%$ \\
Scale 4-SSI & $97.30 \%$ & $92.2 \%-99.4 \%{ }^{\mathrm{a}} \%$ \\
Scale 4-Intv. & $86.40 \%$ & $79.5 \%-93.2 \%$ \\
Scale 1-2 & $99.10 \%$ & $95 \%-99.9 \%$ \\
Scale 1-3 & $92.70 \%$ & $87.4 \%-98 \%$ \\
Scale 1-4 & $94.50 \%$ & $89.8 \%-99.2 \%$ \\
Scale 2-3 & $91.80 \%$ & $86.2 \%-97.4 \%$ \\
Scale 2-4 & $93.60 \%$ & $88.6 \%-98.6 \%$ \\
Scale 3-4 & $87.30 \%$ & $80.6 \%-93.9 \%$ \\
\hline
\end{tabular}

${ }^{\mathrm{a}}$ Confidence interval obtained using the binomial distribution.

monest (25.9\%). Most of the stages reported were in Stage IV (terminal phase) of the illness.
We made an analysis to approximate the sensibility and specificity of our scales, using the complete version of the SSI as reference test. The obtained estimates are considered approximated because the SSI is not a perfect classifier for suicidal ideation, so it is not possible to use it as Gold Standard. We observed the lowest sensibility for Scale 3. Scales 1 and 4 have the highest sensibilities and their confidence intervals are narrower; Scale 2 even though it has the same sensibility value, its confidence interval is the largest one. With respect to the specificities, in all cases we observed high values in the estimates and the confidence intervals are quite narrow (Table 5).

\section{Discussion}

The prevalence of suicidal ideation depends on the index that is used.

The low sensitivity of Item 9 of the BDI is noteworthy. It might be explained by the population's characteristics, indicating that it might be sensitive only in people with high levels of suicidal ideation.

Based on the results of this study, it is valid to question the relevancy of suicidal ideation assessment in the Colombian context based on only one item as in the case of Item 9 of the BDI. It is possible that the Colombian population is not equally sensitive to this item for reasons that have to do with religious beliefs tending to safeguard and respect life, making it more difficult to accept suicidal ideation openly. It is recommended to test this hypothesis and investigate other reasons of a sociocultural nature.

According to the 2003 National Study of Mental Health in Colombia [18], the lifelong prevalence of suicidal ideation in the general population was $12.3 \%$ (ab- 
Table 4. Characterization of the patients with suicidal ideation according to the four proposed scales.

\begin{tabular}{|c|c|c|c|c|c|c|c|c|c|}
\hline & & \multicolumn{2}{|c|}{ Scale $1 \mathrm{~N}=27$} & \multicolumn{2}{|c|}{ Scale $2 \mathrm{~N}=26$} & \multicolumn{2}{|c|}{ Scale $3 \mathrm{~N}=19$} & \multicolumn{2}{|c|}{ Scale $4 \mathrm{~N}=21$} \\
\hline & & Frequency & $\%$ & Frequency & $\%$ & Frequency & $\%$ & Frequency & $\%$ \\
\hline \multirow{3}{*}{$\begin{array}{l}\text { Place of } \\
\text { evaluation }\end{array}$} & Chemotherapy room & 7 & 25.9 & 7 & 26.9 & 3 & 15.8 & 6 & 28.6 \\
\hline & $\begin{array}{l}\text { Room where patient } \\
\text { was hospitalized }\end{array}$ & 14 & 51.9 & 14 & 53.8 & 11 & 57.9 & 11 & 52.4 \\
\hline & Office for outpatients & 6 & 22.2 & 5 & 19.2 & 5 & 26.3 & 4 & 19.0 \\
\hline \multirow{3}{*}{$\begin{array}{l}\text { Age range } \\
\text { (years) }\end{array}$} & 18 to 40 & 10 & 37.0 & 10 & 38.5 & 7 & 36.8 & 7 & 33.3 \\
\hline & 41 to 60 & 13 & 48.1 & 12 & 46.2 & 9 & 47.4 & 10 & 47.6 \\
\hline & $\geq 61$ & 4 & 14.8 & 4 & 15.4 & 3 & 15.8 & 4 & 19.0 \\
\hline \multirow{2}{*}{ Sex } & Feminine & 16 & 59.3 & 15 & 57.7 & 11 & 57.9 & 12 & 57.1 \\
\hline & Masculine & 11 & 40.7 & 11 & 42.3 & 8 & 42.1 & 9 & 42.9 \\
\hline \multirow{4}{*}{ Civil status } & Single & 10 & 37.0 & 10 & 38.5 & 7 & 36.8 & 9 & 42.9 \\
\hline & Married & 10 & 37.0 & 9 & 34.6 & 8 & 42.1 & 7 & 33.3 \\
\hline & Free union & 3 & 11.1 & 3 & 11.5 & 3 & 15.8 & 2 & 9.5 \\
\hline & Separated/divorced & 4 & 14.8 & 4 & 15.4 & 1 & 5.3 & 3 & 14.3 \\
\hline \multirow{3}{*}{ Religion } & Catholic Christian & 19 & 70.4 & 19 & 73.1 & 14 & 73.7 & 15 & 71.4 \\
\hline & Non-Catholic Christian & 7 & 25.9 & 6 & 23.1 & 4 & 21.1 & 5 & 23.8 \\
\hline & Other & 1 & 3.7 & 1 & 3.8 & 1 & 5.3 & 1 & 4.8 \\
\hline \multirow{4}{*}{$\begin{array}{l}\text { Location of } \\
\text { cancer }\end{array}$} & Soft tissues & 9 & 33.3 & 9 & 34.6 & 6 & 31.6 & 8 & 38.1 \\
\hline & Gastrointestinal tract & 8 & 29.6 & 8 & 30.8 & 6 & 31.6 & 7 & 33.3 \\
\hline & Breast & 8 & 29.6 & 7 & 26.9 & 5 & 26.3 & 6 & 28.6 \\
\hline & Reproductive system & 2 & 7.4 & 2 & 7.7 & 2 & 10.5 & 0 & 0.0 \\
\hline \multirow{5}{*}{ Stage } & I & 1 & 3.7 & 1 & 3.8 & 0 & 0.0 & 1 & 4.8 \\
\hline & II & 0 & 0.0 & 0 & 0.0 & 0 & 0.0 & 0 & 0.0 \\
\hline & III & 6 & 22.2 & 5 & 19.2 & 6 & 31.6 & 2 & 9.5 \\
\hline & IV & 7 & 25.9 & 7 & 26.9 & 3 & 15.8 & 6 & 28.6 \\
\hline & Not reported & 13 & 48.1 & 13 & 50.0 & 10 & 52.6 & 12 & 57.1 \\
\hline
\end{tabular}

Table 5. Performance test characteristics for proposed scales using SSI as reference test.

\begin{tabular}{ccccccccc}
\hline & \multicolumn{4}{c}{$\mathrm{N}=110$} & \multicolumn{3}{c}{ CONFIDENCE INTERVALS } \\
\hline Scale & False positives & Subjects & False negatives & Subjects & S & E & SENSITIVITY & SPECIFICITY \\
\hline Selected items SSI & 0.000 & $0 / 91$ & 0.053 & $1 / 19$ & 0.947 & 1.000 & $74.0-99.9$ & $96-100$ \\
Intv. & 0.088 & $8 / 91$ & 0.474 & $9 / 19$ & 0.526 & 0.912 & $28.9-75.6$ & $84.8-97.6$ \\
Item 9 BDI & 0.033 & $3 / 91$ & 0.895 & $17 / 19$ & 0.105 & 0.967 & $1.3-33.1$ & $90.7-99.3$ \\
Scale 1 & 0.099 & $9 / 91$ & 0.053 & $1 / 19$ & 0.947 & 0.901 & $74.0-99.9$ & $83.4-96.8$ \\
Scale 2 & 0.088 & $8 / 91$ & 0.053 & $1 / 19$ & 0.947 & 0.912 & $28.9-75.6$ & $84.8-97.6$ \\
Scale 3 & 0.099 & $9 / 91$ & 0.474 & $9 / 19$ & 0.526 & 0.901 & $28.9-75.6$ & $83.4-96.8$ \\
Scale 4 & 0.033 & $3 / 91$ & 0.053 & $1 / 19$ & 0.947 & 0.967 & $74.0-99.9$ & $90.7-99.3$ \\
\hline
\end{tabular}


solute SE of 0.8) while the12-month prevalence was 3.5\% $(\mathrm{SE}=0.4)$. The prevalence of suicidal ideation among the cancer patients who participated in the study was significantly higher than the prevalence in the general population: $17.3 \%(\mathrm{CI}=9.8 \%-24.8 \%)$ with the SSI and $4.5 \%(\mathrm{CI}=1.5 \%-10.3 \%)$ with Item 9 of the BDI-1A.

Although the prevalence obtained in the Mexican study (20\%) [2] was higher than the highest levels of suicidal ideation in this study (17.3\% with the SSI), the latter is within the range (10.8\% - 71.4\%) indicated in the Robson et al. research [1].

Nonetheless, it is especially interesting that with the proposed scales, the prevalence of suicidal ideation is greater than that obtained with the original complete scales. The prevalences are close to or surpass those of the Vargas-Mendoza study [2]; however, they all definitely prove to be more than double the prevalence of suicidal ideation at the national level, which confirms that it is indeed a condition that can be occur in oncology patients and that its impact can affect their quality of life significantly. In this study we have used the terms "sensitivity" and "specificity" to identify the percentages of individuals, with or without suicidal ideation, classified within the group by reference test. These estimates have a building bias given that the conventionally used test (complete SSI) cannot be assumed as a perfect Gold Standard. However, given that there is no test that meets the condition of being perfect, we approximated the value of the performance parameters of the scales (sensitivity and specificity), taking into account that the values can be under- or over-estimated. It is suggested that further studies be conducted with larger samples and using statistical methods of greater complexity (e.g. latent variables, Bayesian methods) that could not be applied in this study given the methodological limitations and the scope of the study.

\section{Conclusions}

Using the complete SSI as a reference, it is possible to state that given that the confidence-interval overlap, it is possible to use any of the proposed scales or items from the Intv. and the SSI to assess suicidal ideation. This would not occur if only Item 9 of the BDI were used. The SSI is almost the same as Scales 3 and 4, Scale 1 and 2 can be more sensitive. It is recommended to analyze the items in greater depth.

Suicidal behavior in the oncology patient should be assessed; however, this requires selecting sensitive instruments that can be easily applied and that are suitable for the characteristics of the oncology population, which will have difficulties in their capacity to participate in extensive evaluations for diverse factors (e.g. general malaise, distress, secondary effects of the treatment, emotional alterations).
A cancer patient is expected to be courageous, strong and optimistic. An image of a person who never gives up is usually depicted. This high social exigency is antagonistic toward the idea that a person with this illness may contemplate suicide. Therefore, this not only highlights the importance of the patients' receiving psychological care within the framework of integrated care, but also that the results of this study place in evidence the imminent need to address one variable, which in itself increases the perception of suffering in this population and which already exists in their conditions of biological, psychological and social vulnerability. Thus it is essential to consider the need for having instruments that can be applied easily and rapidly, yet that are highly sensitive in order to identify suicidal ideation in adult oncology patients and address it therapeutically in a timely fashion.

As for the limitations of this study, it is clear that the results are not generalizable as they are limited to a particular population; therefore it is recommended to expand and stratify the sample in future studies.

\section{Acknowledgements}

Centro de Investigaciones Oncológicas Clínica San Diego-CIOSAD S.A. We are grateful to the following psychologists who collected the data during the study and who contributed actively to the quality of the students in the last year of their career when they assessed the patients: Diana María Escallón; María Paola Nieto; Andrés Mauricio Novoa; Nidia Yineth Preciado and Silvia María Vergara.

\section{REFERENCES}

[1] A. Robson, F. Scrutton, L. Wilkinson and F. MacLeod, "The Risk of Suicide in Cancer Patients: A Review of the Literature,” Psycho-Oncology, Vol. 19, No. 12, 2010, pp. 1250-1258. http://dx.doi.org/10.1002/pon.1717

[2] J. Vargas-Mendoza, "Evaluación de la Ideación Suicida en Pacientes con Cáncer Sometidos a Quimioterapia," Centro Regional de Investigación en Psicología, Vol. 4, No. 1, 2011, pp. 19-23.

[3] L. Anguiano, D. Mayer, M. Piven and D. Rosenstein, "A Literature Review of Suicide in Cancer Patients,” Cancer Nursing, Vol. 35, No. 4, 2012, pp. 14-26. http://dx.doi.org/10.1097/NCC.0b013e31822fc76c

[4] X. Palacios-Espinosa and J. G. Ocampo-Palacio, "Situación Actual del Conocimiento acerca del Suicidio en las Personas con Cáncer,” Revista Ciencias de la Salud, Vol. 9, No. 2, 2011, pp. 173-190.

[5] I. Spoletini, W. Gianni, C. Caltagirone, R. Madaio, L. Repetto and G. Spalletta, "Suicide and Cancer: Where Do We Go from Here?" Critical Reviews in Oncology/Hematology, Vol. 78, No. 3, 2011, pp. 206-209. http://dx.doi.org/10.1016/j.critrevonc.2010.05.005

[6] L. B. Aiello-Laws, “Assessing the Risk for Suicide in 
Patients with Cancer," Clinical Journal of Oncology Nursing, Vol. 14, No. 6, 2010, pp. 687-691. http://dx.doi.org/10.1188/10.CJON.687-691

[7] M. Barrera and M. Sarmiento, "Ideación Suicida en Niños con Cáncer. Segundo Premio Concurso Nacional de Escritos ACOFAEN,” Avances en Enfermería, Vol. 13. No. 1, 1994, pp. 54-62.

[8] Ministerio de Salud, Instituto Nacional de Cancerología, "Salud y Bienestar. Guía de Apoyo para el Paciente con Cáncer,” Ruecolor Ltda., Bogotá, 1998.

http://www.cancer.gov.co/documentos/Cartillas/pacientec oncancer.pdf

[9] L. Furlanetto and B. Stefanello, "Suicidal Ideation in Medical Inpatients: Psychosocial and Clinical Correlates,” General Hospital Psychiatry, Vol. 33, No. 6, 2011, pp. 572-578. http://dx.doi.org/10.1016/j.genhosppsych.2011.08.002

[10] C. Lefetz and M. Reich, "La Crise Suicidaire en Cancérologie: Évaluation et Prise en Charge,” Bulletin du Cancer, Vol. 93, No. 7, 2006, pp. 709-713.

[11] A. T. Beck, M. Kovacs and A. Weissman, "Escala de Ideación Suicida (SSI)," 1979. www.ucm.es/info/psclinic/evaluacion/index_ppal.htm

[12] D. M. Ndetei, L. Khasakhala and A. W. Mbwayo, "Primary Research Suicidality and Depression among Adult Patients Admitted in General Medical Facilities in Kenya," Annals of General Psychiatry, Vol. 9, No. 7, 2010, pp. 16. http://dx.doi.org/10.1186/1744-859X-9-7

[13] B. H. Wagenaar, A. K. Hagaman, B. N. Kaiser, K. E. McLean and B. A. Kohrt, "Depression, Suicidal Ideation, and Associated Factors: A Cross-Sectional Study in Rural
Haiti,” BMC Psychiatry, Vol. 12, No. 149, 2012, pp. 113. http://dx.doi.org/10.1186/1471-244X-12-149

[14] A. J. Roth and J. C. Holland "Psychiatric Complications in Cancer Patients,” In: M. C. Brain and P. P. Carbone, Eds., Current Therapy in Hematology-Oncology, 5th Edition, Mosby-Year Book, Inc., St. Louis, 1995, pp. 609618.

http://www.cancer.gov/cancertopics/pdq/supportivecare/d epression/HealthProfessional/page5

[15] X. Palacios-Espinosa, N. Y. Preciado, D. M. Escallón and J. G. Ocampo-Palacio, "Entrevista Semiestructurada para la Evaluación de los Factores Sociodemográficos y de la Conducta Suicida (Ideación e Intención) y los Factores Asociados con esta en Pacientes con Cáncer Adultos,” Unpublished.

[16] E. Baca-Garcia, M. M. Pérez-Rodriguez, M. A. Oquendo, K. M. Keyes, D. S. Hasin, B. F. Grant and C. Blanco, "Estimating Risk for Suicide Attempt: Are We Asking the Right Questions? Passive Suicidal Ideation as a Marker for Suicidal Behavior," Journal of Affective Disorders, Vol. 134, No. 1, 2011, pp. 327-332. http://dx.doi.org/10.1016/j.jad.2011.06.026

[17] Resolución 008430 de 1993. Por la cual se establecen las Normas Científicas, Técnicas y Administrativas para la Investigación en salud. República de Colombia Ministerio de salud. http://www.dib.unal.edu.co/promocion/etica_res_8430_1 993.pdf

[18] Ministerio de Protección Social, "Estudio Nacional de Salud Mental-Colombia 2003,” Ministerio de la Protección Social y Fundación FES Social, Cali, 2005. 